\title{
REVISTAS ACADÊMICAS COMO AGENTES DO CAMPO CIENTÍFICO DE ADMINISTRAÇÃO
}

\author{
Academic journals as agents of the scientific field of Administration \\ Revistas académicas como agentes del campo científico de la Administración
}

\author{
Alketa Peci' ${ }^{1}$ alketa.peci@fgv.br| ORCID: 0000-0002-0488-1744 \\ Lilian Alfaia Monteiro² | lilian.alfaia@ufjf.edu.br | ORCID: 0000-0001-5891-1788 \\ ${ }^{1}$ Fundação Getulio Vargas, Escola Brasileira de Administração Pública e de Empresas, Rio de Janeiro, RJ, Brasil \\ ${ }^{2}$ Universidade Federal de Juiz de Fora, Faculdade de Administração e Ciências Contábeis, Juiz de Fora, MG, Brasil
}

\begin{abstract}
RESUMO
Revistas acadêmicas são importantes atores do campo científico de Administração, entendido como um espaço caracterizado por uma lógica própria de jogo, onde diversos agentes competem, recorrendo a vários tipos de capitais, para determinar o monopólio da autoridade científica. Como as revistas acadêmicas acompanham e refletem a dinâmica do campo de Administração no Brasil? Como esses atores se posicionam nesse espaço? 0 trabalho evidencia como as revistas acadêmicas evoluem acompanhando a dinâmica do campo e reforçando estratégias de legitimação da contribuição científica. Por fim, discutimos os atuais desafios de internacionalização para as revistas da área.
\end{abstract}

PALAVRAS-CHAVE | Revistas acadêmicas, campo científico de Administração, legitimação, retórica, internacionalização.

\section{ABSTRACT}

Academic journals are important actors in the scientific field of Administration, understood as a space characterized by a logic of its own, where several agents compete and resort to various types of capital in order to determine the monopoly over scientific authority. How do academic journals follow and reflect the dynamic of the Administration field in Brazil? How do these actors take their positions in this space? This article shows how academic journals evolve as they follow the field's dynamic and reinforce strategies for legitimizing scientific contribution. Finally, we discuss the current internationalization challenges for journals in the area.

KEYWORDS I Academic journals, scientific field of Administration, legitimation, rhetoric, internationalization.

\section{RESUMEN}

Las revistas académicas son actores importantes del campo científico de la Administración, entendido como un espacio caracterizado por su propia lógica de juego, donde diferentes agentes compiten, recurriendo a diversos tipos de capital, para determinar el monopolio de la autoridad científica. ¿Cómo siguen y reflejan las revistas académicas la dinámica del campo de la Administración en Brasil? ¿Cómo se posicionan esos actores en este espacio? El trabajo muestra cómo las revistas académicas evolucionan siguiendo la dinámica del campo y reforzando estrategias para legitimar la contribución científica. Finalmente, discutimos los desafíos actuales de internacionalización para las revistas del área.

PALABRASCLAVE/Revistas académicas, campo científico de la Administración, legitimación, retórica, internacionalización. 


\section{INTRODUÇÃO}

O surgimento do campo de Administração como campo distinto de conhecimento respondeu à consolidação da reforma administrativa da Era Vargas e ao projeto industrial-desenvolvimentista em curso no País desde os anos 1930, e materializou-se pelo estabelecimento dos primeiros cursos de Administração a partir dos anos 1940 e 1950 (Barros \& Carrieri, 2013). Vários trabalhos analisaram aspectos importantes do novo campo, como a formação dos administradores (Motta, 1983), os saberes administrativos (Barros, Cruz, Xavier, \& Carrieri, 2011; Curado, 2001), o ensino e o estabelecimento dos cursos de graduação em Administração (Barros, 2011; Barros \& Carrieri, 2013; Fischer, 1984a, 1984b, 1993, 2010; Fischer et al., 2011; Nicolini, 2007) ou em Administração Pública (Coelho, 2006; Coelho, Olenscki, \& Celso, 2010; Nicolini, 2003).

Em poucas décadas, esse campo prolifera numericamente em várias dimensões: milhares de cursos de graduação e dezenas de programas de pós-graduação (Bertero, 2003), fortalecimento de associações como a Associação Nacional de Pós-graduação e Pesquisa em Administração (ANPAD), que passa de oito programas de pós-graduação fundadores em 1976 para mais de 190 programas hoje, milhares de participantes em encontros científicos da área (EnANPAD), multiplicação de eventos acadêmicos e consolidação de critérios de avaliação institucional e individual que premiam ou punem a qualidade e a produtividade, ao exemplo do processo de credenciamento da Coordenação de Aperfeiçoamento de Pessoal de Nível Superior (CAPES), ou das bolsas de produtividade do Conselho Nacional de Desenvolvimento Científico e Tecnológico (CNPq) (Peci \& Alcadipani, 2006).

A dinâmica das revistas acadêmicas de Administração acompanha e reflete esse crescimento quantitativo do campo. As primeiras revistas surgem nos anos 1960 - Rausp Management Journal (RAUSP), Revista de Administração Pública (RAP) e Revista de Administração de Empresas (RAE) - e dominam a produção científica do campo por várias décadas. Essa produção começa a crescer gradualmente nas décadas de 1980-1990, mas o salto quantitativo dá-se a partir de 2000. Hoje existem mais de 300 revistas acadêmicas no campo de Administração (Rosa \& Romani-Dias, 2019a). Pouco conhecemos, ainda, sobre como esses atores se posicionam no campo científico de Administração e como, ainda, se diferenciam entre eles.

Este artigo parte da premissa de que os periódicos são atores-chave que marcam a dinâmica do campo científico de Administração. De fato, as revistas acadêmicas cumprem uma dupla função: são os principais meios de comunicação da produção científica de um campo para seus membros internos (pesquisadores) e externos (mídia, sociedade); são, simultaneamente, agentes importantes do campo científico de Administração, ao lado dos pesquisadores, programas, associações e outros atores relevantes que marcam sua dinâmica.

A partir de uma visão construtivista do campo científico, concebido como um espaço marcado por uma lógica própria de jogo, permeado por relações de poder, onde agentes disputam o monopólio da autoridade científica recorrendo a diversos tipos de capitais (Bourdieu, 1983; Flingstein \& McAdam, 2012), neste trabalho, refletimos sobre a evolução histórica do campo da Administração e sobre o posicionamento das revistas acadêmicas nessa trajetória. Tendo como recorte a área de Estudos Organizacionais, analisamos retoricamente 500 artigos científicos nacionais e internacionais, publicados nas revistas da área ao longo de seis décadas, e identificamos: a) como evoluem as revistas científicas do campo; b) quais são as principais estratégias de legitimação que sustentam o que é uma contribuição científica; c) como essas estratégias refletem o crescimento qualitativo e quantitativo do campo de Administração. Finalmente, analisamos os desafios impostos pelas métricas de internacionalização e defendemos que a contribuição das revistas acadêmicas no Brasil para o desenvolvimento do conhecimento em Administração precisa ser vista à luz do jogo de poder do campo, atualmente ameaçado pelo recorte de recursos públicos que sustentou sua expansão quantitativa ao longo das últimas décadas. 


\section{ADMINISTRAÇÃO COMO UM CAMPO CIENTÍFICO}

Um campo é uma arena social de nível meso, marcado por uma lógica distinta de jogo, permeado por relações de poder e caracterizado por jogadores e regras de jogo próprios (Bourdieu, 1983, 1991; Davis \& Marquis, 2005; Flingstein \& McAdam, 2012). O campo científico pode ser entendido como um espaço caracterizado por uma luta concorrencial pelo monopólio da autoridade científica, um espaço de competição no qual agentes individuais e coletivos trabalham para valorizar o seu próprio capital, por meio de estratégias de acumulação impostas pela concorrência e apropriadas para determinar a preservação ou transformação da estrutura (Bourdieu, 1983, 1991; Davis \& Marquis, 2005; Martin, 2003).

Na disputa em torno do jogo, o monopólio pela superioridade da autoridade científica torna-se objeto de rivalidade entre os jogadores-atores, entendidos aqui como acadêmicos, instituições de ensino/pesquisa, revistas científicas ou até mesmo redes de pesquisadores, orientando suas estratégias de ação e relacionamentos. Esses atores individuais e coletivos recorrem a vários recursos como uma forma de legitimação no âmbito do campo científico, conforme demonstram análises da dinâmica das relações de poder em diversos campos científicos (Burri, 2008; Hong, 2008; Klenk, Hickey, \& Maclellan, 2010).

A Figura 1 resume a dinâmica do campo científico de Administração, destacando os pesquisadores, os programas acadêmicos e as revistas científicas como os principais agentes desse campo que competem na busca do monopólio da autoridade científica. A evolução do campo é marcada por vários fatores, entre os quais destacamos a disponibilidade de recursos e financiamento (públicos ou privados) e o papel de unidades de governança como CAPES e CNPq, as quais, com as suas regras, estimulam uma dinâmica de competição no campo (rankings). Adicionalmente, a figura destaca que, para o campo científico, alguns tipos de capitais (linguístico, social) se revelam mais importantes que outros, assumindo o status de capital simbólico.

Figura 1. O jogo do campo científico: Lógica, atores e capitais

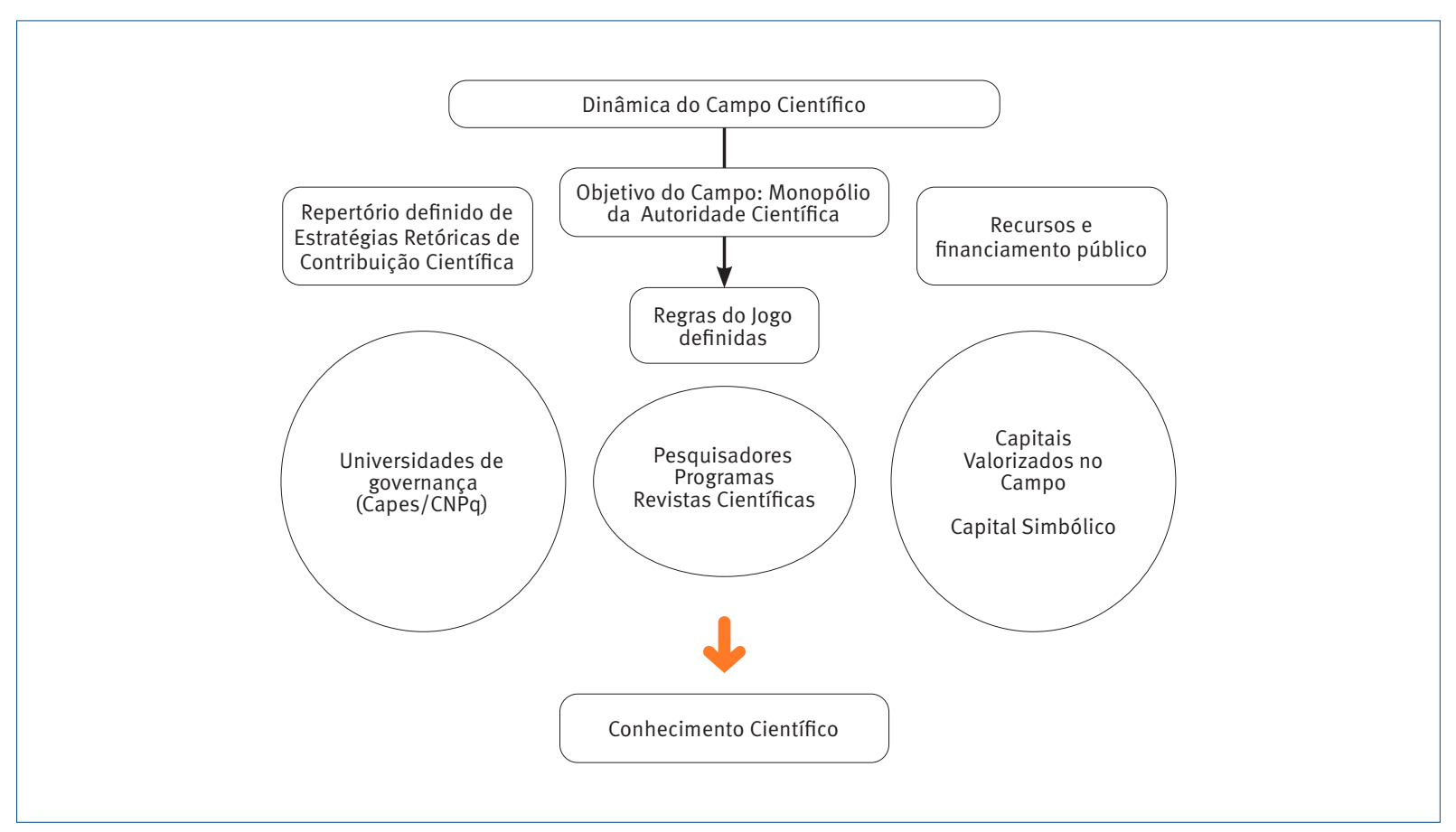


O conhecimento científico é produto desse campo de poder e suas dinâmicas. Em outras palavras, artigos veiculados nas principais revistas da área também refletirão essa dinâmica e serão objeto deste trabalho.

\section{METODOLOGIA}

Para identificar, a partir de uma ótica longitudinal, a evolução da produção científica resultante da evolução do campo, com um recorte em Estudos Organizacionais, apresentamos aqui os resultados de uma pesquisa que analisou um conjunto de artigos científicos publicados entre os anos 1960 e o ano de 2014.

Tomamos como referência o estudo de Locke e Golden-Biddle (1997), e apresentamos a análise relativa às estratégias retóricas que definem e diferenciam uma contribuição científica. Foi construída uma base de dados no Excel que centralizou as informações em torno dos artigos publicados no período de 1960 a 2014. A partir dos artigos, foram coletadas informações relativas às regras de jogo de um campo científico: publicação em revistas (atualmente ranqueadas); programas de vinculação institucional (atualmente ranqueados) e bolsas de produtividade em pesquisa CNPq (atualmente ranqueados). Também foram consideradas informações relativas ao ano de publicação, categorias de estratégias de legitimidade de contribuição científica, autor(es) e país de formação acadêmica. A ideia de reunir esses dados distribuídos em torno das regras de jogo do campo justificou-se em função de muitos serem considerados uma possibilidade para indicar as tomadas de posição e posições dos agentes, tais como estrato Qualis do periódico, nota do programa de vinculação e categorias de estratégias de legitimidade de contribuição científica. 0 estrato Qualis CAPES dos periódicos também pode ser um indicativo do capital científico dos agentes. Já os autores e instituições de vínculo são considerados fundamentais para relacionar as estratégias de legitimidade de contribuição científica, por serem os agentes individuais e coletivos presentes no campo. Os dados sobre bolsistas de produtividade em pesquisa CNPq, além de poderem ser interpretados como indicadores do posicionamento no campo, também se colocam como um dado referente ao capital econômico. Desses 500 artigos, 430 foram publicados em periódicos nacionais e 70, em periódicos estrangeiros, tendo estes sido escritos por pesquisadores brasileiros bolsistas de produtividade do CNPq. A inclusão desses artigos na pesquisa deu-se em função de uma possível comparação entre as estratégias de legitimidades de contribuição científica utilizadas nesses dois tipos de periódicos.

Essa coleta foi feita a partir de cortes temporais que permitiram analisar as décadas de 1960, 1970, 1980, 1990 e 2000 e o período 2010-2014. A quantidade de artigos analisados por década pode ser encontrada na Tabela 1 a seguir:

Tabela 1. Quantidade de artigos analisados por década

\begin{tabular}{l|c}
\hline Período Analisado & Quantidade \\
\hline Anos 1960 & 9 \\
\hline Anos 1970 & 18 \\
\hline Anos 1980 & 23 \\
\hline Anos 1990 & 54 \\
\hline Anos 2000 & 190 \\
\hline Anos 2010 & 206 \\
\hline
\end{tabular}


Conforme será mais detalhado a seguir, a pesquisa ajuda a compreender a produção científica veiculada nas revistas do nosso campo à luz das estratégias discursivas a que os atores recorrem e como estas são manejadas empiricamente, ajustando-se às posições sociais e aos recursos dos agentes que disputam a autoridade no campo. Por fim, a análise permite compreender como os principais agentes, incluindo as revistas, se posicionam no campo científico de Administração a partir dos anos 2000.

\section{ANÁLISE LONGITUDINAL DO CAMPO}

A produção científica nacional em Estudos Organizacionais teve seu início a partir dos anos 1960, com o surgimento das primeiras revistas em Administração, RAUSP, RAP e RAE. A essa época, a produção era bem escassa e, dos poucos artigos publicados, muitos eram de autores estrangeiros e se tratavam ou de traduções de artigos publicados em periódicos internacionais ou de produções realizadas por professores estrangeiros convidados para ministrar cursos no âmbito de programas de cooperação entre universidades internacionais americanas e brasileiras, tal como ocorreu na FGV EAESP (Alcadipani \& Bertero, 2012). Além de poucas revistas nessa época, o número de edições também era pequeno, assim como se mostrou nos anos 1970. A partir dos anos 1980 e 1990 , a produção cresceu pouco a pouco, mas foi a partir dos anos 2000 que ocorreu um salto quantitativo, reunindo $78 \%$ do total dos 500 trabalhos analisados.

O crescimento observado reflete a criação de novos programas e, principalmente, de novas revistas a partir dos anos 1900. O campo muda pela inserção de novos agentes, individuais e coletivos, iniciando sua consolidação. É nessa década que o CNPq cria a Plataforma Lattes e o Diretório dos Grupos de Pesquisa, instrumentos fundamentais para as atividades de fomento, avaliação, acompanhamento e direcionamento para políticas e diretrizes de incentivo à pesquisa. Em 1998, a CAPES muda a escala de conceituação para avaliação da pós-graduação para o sistema numérico de 1 a 7, assumindo o papel de unidades de governança, supervisionando o cumprimento das regras do campo e o bom funcionamento geral, e facilitando a reprodução do sistema (Fligstein \& McAdam, 2011, 2012).

A partir dos anos 2000, o campo consolida-se significativamente, passando a receber maior número de programas de pós-graduação, pesquisadores, alunos, triplicando sua produção em relação à década anterior. Começam a predominar as relações de coautoria, justificadas pela pressão por publicações e também como uma consequência do próprio crescimento do campo, que apresenta maior número de grupos de pesquisa e colaborações interinstitucionais. As produções de autoria única passam a ser a categoria de menor ocorrência (Tabela 2), revelando a importância do capital social no campo (Bourdieu, 1998).

Tabela 2. Tipos de autoria - Artigos nacionais - de 1960 a 2014

\begin{tabular}{|c|c|c|c|c|c|c|c|c|}
\hline Tipo de autoria & 1960 & 1970 & 1980 & 1990 & 2000 & $2010-2014$ & Qde. & (\%) \\
\hline Única & 9 & 15 & 17 & 39 & 51 & 18 & 149 & 34,65 \\
\hline Coautoria 2 & 0 & 2 & 5 & 11 & 69 & 78 & 165 & 38,37 \\
\hline Coautoria 3 & 0 & 0 & 1 & 3 & 34 & 42 & 80 & 18,60 \\
\hline Coautoria $4^{+}$ & 0 & 0 & 0 & 0 & 10 & 26 & 36 & 8,37 \\
\hline Total & 9 & 17 & 23 & 53 & 164 & 164 & 430 & 100 \\
\hline
\end{tabular}

Fonte: Dados da pesquisa. 
A partir de 2005, após um crescimento quantitativo na pós-graduação, a CAPES induz uma mudança qualitativa na avaliação da produção científica, incluindo novas diretrizes que marcam novamente as revistas, como fatores de impacto e de citação no processo de avaliação e indicadores relativos à expressão científica no contexto nacional e internacional, aperfeiçoando uma vez mais suas estratégias como unidade de governança no campo (Fligstein \& McAdam, 2011, 2012).

O crescimento quantitativo entre os anos 2010 a 2014 se mantém, e se equipara à produção da década anterior, refletindo o alto número de programas, consequência da crescente disponibilidade de recursos e financiamento público. Conforme exemplificado na Tabela 3, os investimentos do CNPq na área de Administração tiveram crescimentos consideráveis nos anos de 2012 e 2013, dobrando de volume em relação ao ano anterior, ocupando a $10^{\underline{a}}$ posição no ranking de investimentos realizados no ano de 2014.

Tabela 3. CNPq - Investimentos realizados em bolsas e no fomento à pesquisa em Administração - 20012014 (ranking com base no total de investimentos em 2014)

\begin{tabular}{|c|c|c|c|c|c|c|c|c|c|c|c|c|c|c|c|}
\hline \multirow[t]{2}{*}{ Rk } & \multirow{2}{*}{$\begin{array}{c}\text { Área do } \\
\text { conhecimento }\end{array}$} & \multicolumn{14}{|c|}{ Investimentos (Reais mil correntes) } \\
\hline & & 2001 & 2002 & 2003 & 2004 & 2005 & 2006 & 2007 & 2008 & 2009 & 2010 & 2011 & 2012 & 2013 & 2014 \\
\hline 10 & Administração & 9.425 & 8.399 & 7.551 & 8.151 & 7.336 & 8.226 & $9 \cdot 988$ & 9.607 & 10.740 & 15.574 & $15 \cdot 561$ & 34.764 & 72.944 & 77.041 \\
\hline
\end{tabular}

Fonte: CNPq - Investimentos realizados em bolsas e no fomento à pesquisa segundo áreas do conhecimento - 2001-2014.

Disponível em: http://memoria.cnpq.br/documents/10157/77140dge-5698-4242-8e53-2a72cd7ff1d7 Acesso em: março/2021

Sobre a distribuição dos artigos em Estudos Organizacionais nos periódicos brasileiros, percebemos a permanência de revistas pioneiras, como RAE e RAP, que lideram o volume de artigos. Novos atores surgem, como a revista Cadernos EBAPE.BR, em 2003, com uma produção bastante significativa para um período de 11 anos. A revista Organizações \& Sociedade (O\&S), criada em 1993, aparece em seguida, reforçando sua relação com o tema de Estudos Organizacionais (Tabela 4).

Tabela 4. Distribuição dos artigos nos periódicos brasileiros

\begin{tabular}{l|c|c}
\hline Periódico & Artigos & (\%) \\
\hline RAE & 73 & 16,98 \\
\hline RAP & 67 & 15,58 \\
\hline Cadernos EBAPE.BR & 46 & 10,70 \\
\hline O\&S & 31 & 7,21 \\
\hline Revista de Administração Mackenzie & 30 & 6,98 \\
\hline RCA-Revista de Ciências da Administração & 28 & 6,51 \\
\hline RAC-Revista de Administração Contemporânea & 24 & 5,58 \\
\hline REGE-Revista de Gestão & 23 & 5,35 \\
\hline Gestão e Planejamento & 17 & 3,95 \\
\hline REAd - Revista Eletrônica de Administração & 14 & 3,26 \\
\hline Economia \& Gestão & 11 & 2,56 \\
\hline Rausp & 11 & 2,56 \\
\hline RAU-Revista de Administração & 7 & 1,63 \\
\hline RECADM-Revista Eletrônica de Ciência Administrativa & 7 & 1,63 \\
\hline
\end{tabular}


ARTIGOS | REVISTAS ACADÊMICAS COMO AGENTES DO CAMPO CIENTÍFICO DE ADMINISTRAÇÃO

Alketa Peci | Lilian Alfaia Monteiro

Tabela 4. Distribuição dos artigos nos periódicos brasileiros

Conclui

\begin{tabular}{|c|c|c|}
\hline Periódico & Artigos & (\%) \\
\hline Desenvolvimento em Questão & 6 & 1,40 \\
\hline FACES & 6 & 1,40 \\
\hline Gestão e Tecnologia & 6 & 1,40 \\
\hline Pretexto & 5 & 1,16 \\
\hline RGO - Revista Gestão Organizacional & 5 & 1,16 \\
\hline Alcance & 3 & 0,70 \\
\hline Revista de Administração da UFSM & 3 & 0,70 \\
\hline Contextus & 2 & 0,47 \\
\hline RBGN - Revista Brasileira de Gestão de Negócios & 2 & 0,47 \\
\hline BAR - Brazilian Administration Review & 1 & 0,23 \\
\hline BASE - Revista de Administração e Contabilidade da Unisinos & 1 & 0,23 \\
\hline Gestão e Regionalidade & 1 & 0,23 \\
\hline Total & 430 & 100 \\
\hline
\end{tabular}

Fonte: Dados da pesquisa.

O Gráfico 1 representa a evolução longitudinal do campo em torno dos seus agentes-chave. 0 levantamento de bolsistas de produtividade em pesquisa CNPq começa a partir de 1998 devido ao fato de esses dados estarem sistematizados somente a partir dessa data na instituição.

Gráfico 1. Evolução longitudinal de bolsistas, programas e revistas - de 1961 a 2014

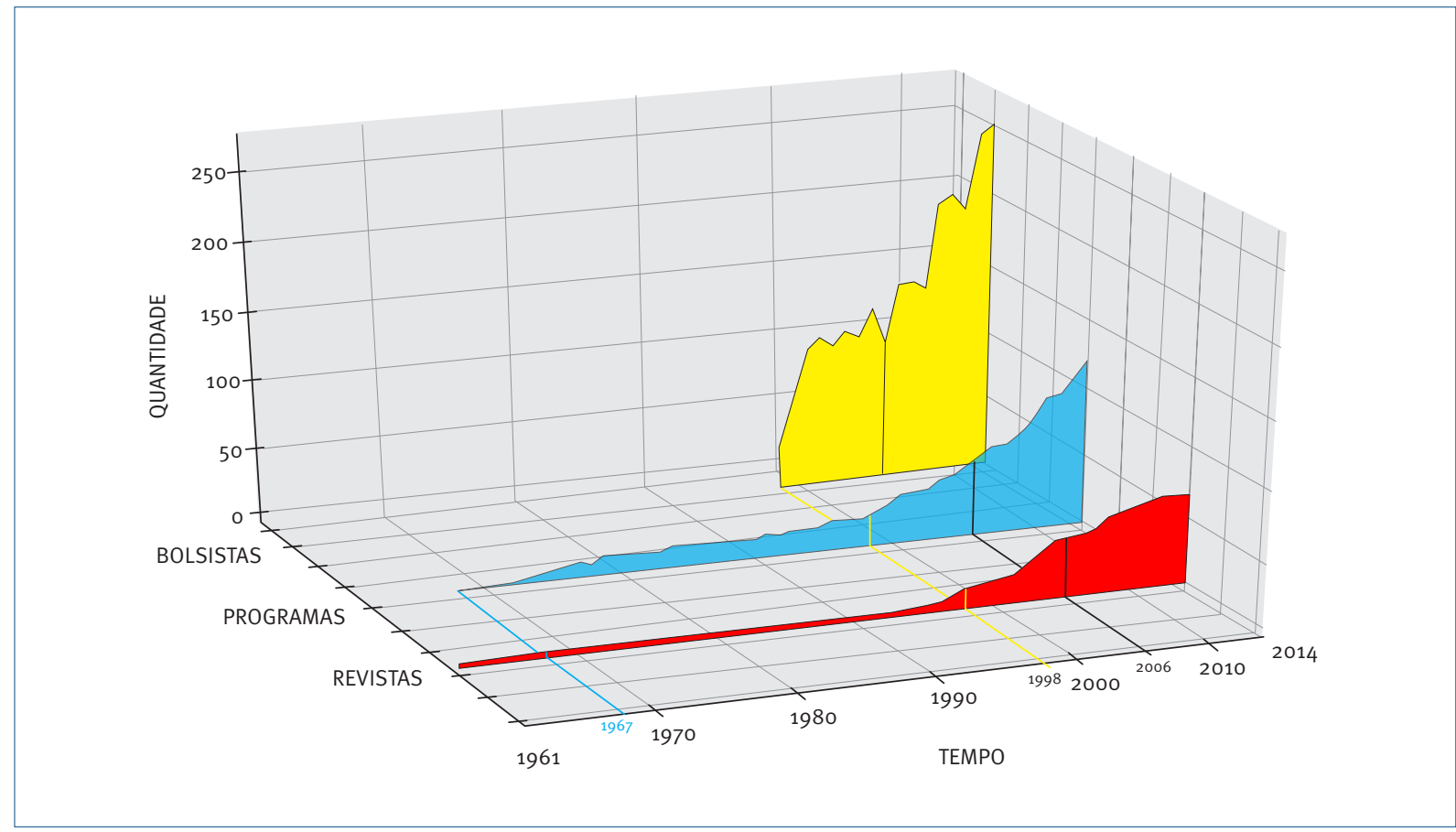

Fonte: Dados da pesquisa. 
A partir dos anos 2000, as publicações em revistas internacionais tornam-se mais substanciais, correspondendo a $33 \%$ da produção. Antes disso, a internacionalização consistia apenas em publicações pontuais. De 2010 a 2014, a produção já dobra de volume se comparada à década anterior. Esse período coincide com aumentos em relação aos investimentos em bolsas e fomentos em pesquisa pelo CNPq (vide Tabela 3), com reflexos dos ajustes de avaliação da CAPES em relação aos conceitos dos programas, periódicos e indicadores de produção científica e também com o maior número de programas e pesquisadores no campo.

\section{Estratégias de legitimação da contribuição científica}

De que forma os artigos constroem suas contribuições científicas na tentativa de se legitimarem em um campo científico? Para responder a essa questão, recorremos à análise retórica de textos científicos (Gusfield, 1976), que nos permitiu identificar as principais estratégias de legitimação (Locke \& Golden-Biddle, 1997) presentes nas publicações.

A proposta dessa análise retórica é incorporar não somente o conteúdo das argumentações ou afirmações, mas também como elas dão suporte e rendem créditos ao texto, tendo como foco central a identificação de características textuais e práticas retóricas que ajudarão a suportar a validade dos argumentos (Locke \& Golden-Biddle, 1997). Assim, as estratégias de legitimidade identificadas nos textos analisados foram categorizadas a partir de uma análise de conteúdo (Bardin, 2006), A unidade de análise tomada como referência para a análise categorial foi o tema. Para a definição das categorias, optamos por uma grade de análise mista.

Para essa categorização, analisamos a introdução dos artigos, tendo em vista que, em geral, é nesse tópico que os autores apresentam e defendem as contribuições de seus trabalhos. Foram considerados os trechos em que os autores argumentavam sobre a importância ou o diferencial de seu trabalho perante o estado do campo, sobre o porquê da escolha do objeto de estudo e sobre as contribuições oferecidas pelo estudo. Esse processo produziu 1.062 segmentos de textos. Ao final, os dados relativos à categorização foram inseridos na base de dados. A fim de conferir maior confiabilidade à categorização, procedemos a uma dupla e independente checagem nessa etapa, feita com base em uma amostra de 50 artigos, isto é, 10\% da amostra trabalhada no estudo (Gaskell \& Bauer, 2005; Kirk \& Miller, 1986).

Desse modo, chegamos às quatro grandes categorias sobre as estratégias de legitimação das contribuições científicas presentes neste trabalho: discurso científico interno, discurso científico externo, discurso da prática e discurso da diferenciação. Além disso, também identificamos a categoria sem discurso específico e mais 11 diferentes combinações das quatro principais categorias que eventualmente apareceram nos textos dos artigos. As categorias e suas definições se resumem no Quadro 1.

A análise revelou que o DCl e o DP, assim como uma combinação dos dois (DCIP), são as principais estratégias de legitimação historicamente utilizadas no campo. É possível notar a distribuição e evolução das estratégias de legitimidade mais predominantes e perceber como, até os anos 1990, apesar de haver diferenças, esses discursos estavam mais próximos e como, a partir dos anos 2000, o DCl dá um salto quantitativo em relação ao DP e ao DCIP (Gráfico 2).

Nos periódicos internacionais, observamos um predomínio do $\mathrm{DCl}$ em relação às demais estratégias de legitimidade. O DCIP também aparece, em menor grau (21,42\%), como a segunda estratégia mais utilizada pelos autores. Percebemos, assim, que o DCl aparece em $72,84 \%$ das publicações, mostrando ser a estratégia preferida pelos autores que publicam internacionalmente. 0 uso massivo dessa estratégia em artigos internacionais deve-se, provavelmente, às exigências dos periódicos estrangeiros em explicitar as contribuições científicas dos trabalhos. Diferente dos artigos nacionais, aqui o DP não aparece como uma das estratégias de legitimidade mais utilizadas e, assim como outras categorias, apresenta baixa ocorrência no conjunto de artigos analisados, particularmente presente nas décadas iniciais. 
Quadro 1. Estratégias de legitimidade de contribuição científica

\begin{tabular}{l|c}
\hline Categorias e Definições & Código \\
\hline Discurso científico interno & $\mathrm{DCl}$ \\
\hline
\end{tabular}

Conjunto de estratégias de legitimidade de contribuição científica que têm como ponto de referência o próprio campo científico, isto é, são estratégias utilizadas por pesquisadores que se referem a outros pesquisadores do próprio campo.

Discurso científico externo

DCE

Estratégias de legitimidade de contribuição científica que têm como ponto de referência outros campos científicos, isto é, são estratégias utilizadas por pesquisadores de Estudos Organizacionais que dialogam com outros trabalhos científicos exteriores à Administração, justificando o estudo a partir de temas comuns e explorados por outras disciplinas.

Discurso da prática

DP

Conjunto de estratégias de legitimidade de contribuição científica que consistem na contribuição que privilegia problemas práticos, soluções para as organizações ou para a sociedade de modo geral e focam a relevância prática da pesquisa acadêmica. Apresenta uma fala não só para o meio científico-acadêmico, mas também para outros atores da sociedade

Discurso da diferenciação

DD

Estratégia de legitimidade de contribuição científica que defende suas contribuições por meio da assimilação crítica ou adaptação de teorias estrangeiras à realidade local, e não somente uma simples repetição ou aplicação direta e acrítica de um modelo estrangeiro.

Sem discurso específico

SDE

\section{Gráfico 2. Evolução das estratégias de legitimidade predominantes em artigos nacionais - de 1960 a 2014}

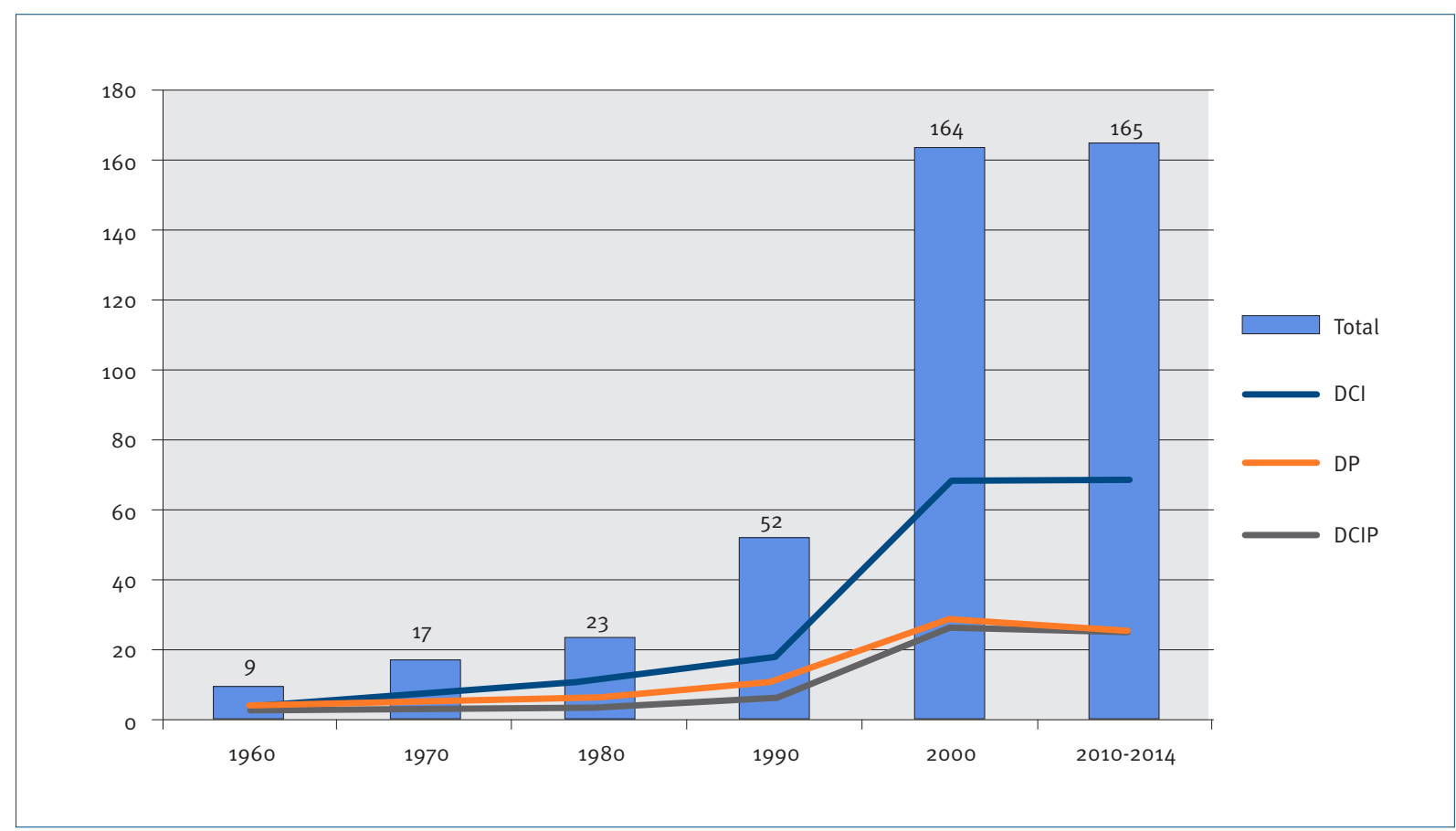

Fonte: Dados da pesquisa. 
Conforme podemos ver no Gráfico 3, as estratégias de legitimidade DCl e DCIP acompanham o surgimento efetivo da produção internacional a partir dos anos 2000. Em termos absolutos, a estratégia de legitimidade DCl aumenta, apesar de, em termos relativos, seu percentual ter diminuído no período de 2010 a 2014, se comparado aos anos 2000. Apesar dessas diferenças, nos dois modos de comparação, o DCl ainda aparece como a estratégia mais utilizada.

Gráfico 3. Evolução das estratégias de legitimidade predominantes em artigos internacionais - de 1960 a 2014

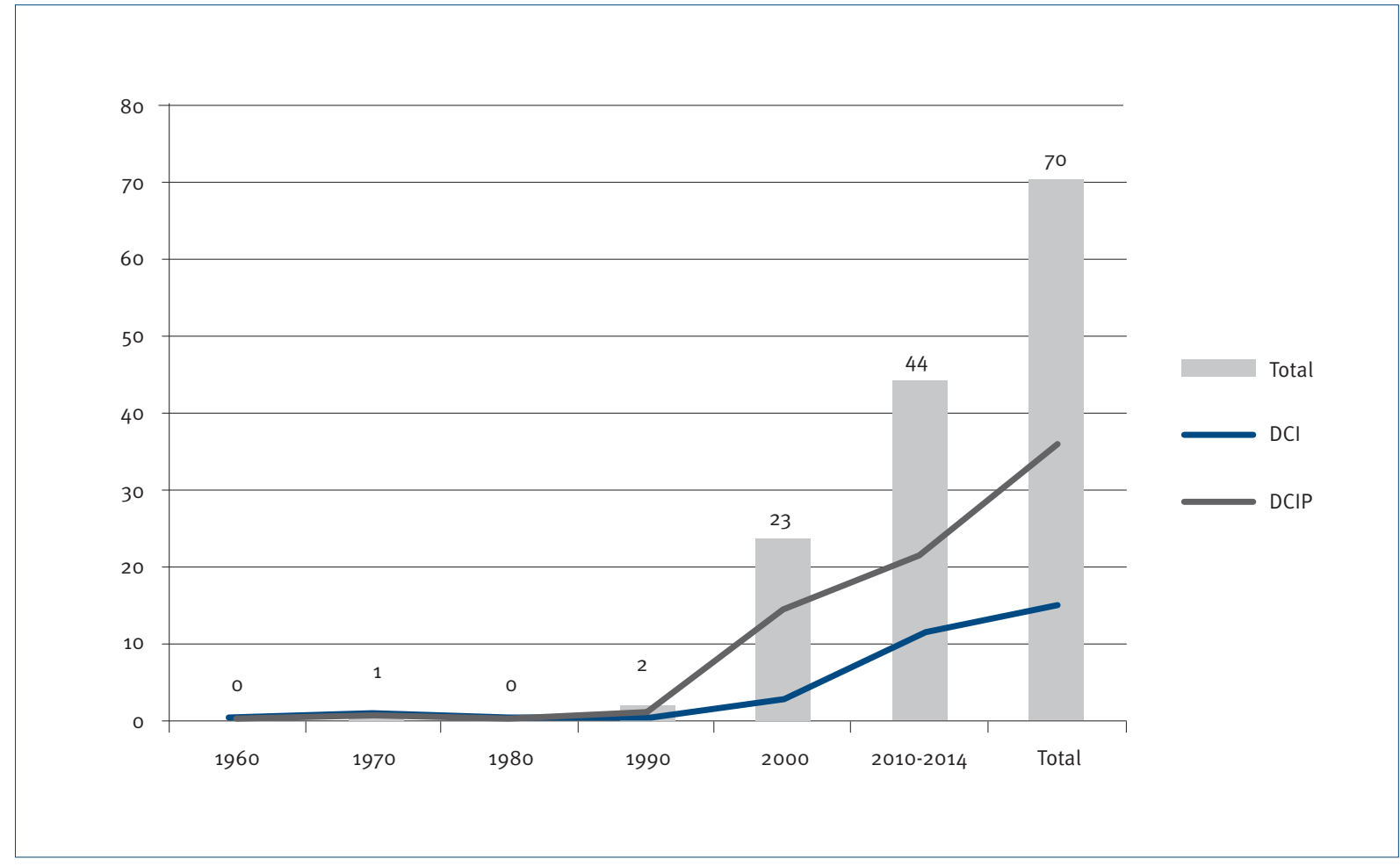

Fonte: Dados da pesquisa.

\section{Discurso da prática (DP) - Anos 1960 e 1970}

Considerando a porcentagem de ocorrência em relação ao total da produção em cada período, o DP foi uma estratégia de legitimidade mais marcante no início do campo, entre os anos 1960 e 1970, mas foi diminuindo aos poucos, à medida que os anos passavam e o campo ia se estruturando, não tendo, porém, desaparecido. Como a maturação do campo de Estudos Organizacionais requeria o desenvolvimento e a consolidação de instâncias mais acadêmicas, a fim de se firmar como campo científico, é de se compreender o porquê de essa estratégia de legitimidade ter aparecido de modo mais predominante nos períodos iniciais do campo. A própria fala nesse tipo de estratégia de legitimidade, dirigida a outros atores da sociedade, sobretudo do meio organizacional, faz mais sentido em uma época em que o campo acadêmico não era tão fortalecido (ver Curado, 2001).

É importante ressaltar que o DP, mesmo tendo aparecido em menor proporção ao considerar o total da produção, foi aumentando em termos de quantidade, acompanhando o aumento da produção no campo. Isso mostra que ele não desapareceu e, por ser a segunda estratégia de legitimação de contribuição científica mais 
utilizada pelos autores, deve ser considerado ainda como uma importante forma de legitimidade do conhecimento científico no campo.

\section{Discurso científico interno e da prática (DCIP) - anos 1970 e 2000 em diante}

A estratégia de legitimidade do DCIP teve predominância nos anos 1970, início do campo, e foi retomada mais tarde, a partir dos anos 2000, momento de consolidação do campo, até 2014, final do período analisado. Importante frisar que sua predominância nos anos 1970 se deu somente na produção nacional, já que quase não havia produção internacional de autores brasileiros a essa época. Já a retomada a partir dos anos 2000 aconteceu nas publicações nacionais e também foi predominante na produção internacional.

Essa retomada deu-se combinando e associando o DCl, que já estava bastante fortalecido nesse período, ao DP, que estava se enfraquecendo como estratégia, compondo a nova categoria DCIP. Desse modo, o DP pôde ganhar novo impulso, uma vez que estivesse associado ao $\mathrm{DCl}$.

A predominância da estratégia de legitimidade DCIP deve ser compreendida de modo contextualizado com a evolução do conhecimento em Administração, que, apesar de ter se estruturado como um campo científico, não perdeu sua relação com a aplicabilidade de suas contribuições, afinal a Administração se situa como ciência social aplicada, e por isso não perde seu caráter prático. Em virtude disso, apesar de não ser a estratégia mais recorrente na análise, o DCIP mostra-se relevante na área devido à junção que realiza entre o enfoque prático, que ainda se mostra presente, e o viés acadêmico-científico desenvolvido na trajetória do campo.

\section{Discurso científico interno (DCl) - Anos 1980 em diante}

O DCl esteve presente em todas as décadas na produção nacional e destaca-se a partir dos anos 1980, período ainda de estruturação do campo. Mas se torna ainda mais marcante a partir dos anos 2000 , período em que 0 campo se consolida e atinge um grau elevado de elementos como programas, recursos, revistas e pesquisadores, aumentando a disputa entre os agentes e o papel das unidades de governança. Na produção internacional, o $\mathrm{DCl}$ aparece a partir dos anos 2000, juntamente com o aparecimento dessas publicações, quando começou a haver maiores incentivos e pressões por parte dos programas e agências de fomento à pesquisa para que os pesquisadores brasileiros publicassem em periódicos estrangeiros, preferencialmente nos bem-avaliados pela CAPES.

O aumento considerável do $\mathrm{DCl}$ nas últimas décadas, associado ao aumento e fortalecimento dos elementos destacados acima, é um indicativo do amadurecimento científico do campo, principalmente se levarmos em consideração que a ocorrência do DP isoladamente diminui, enquanto a combinação DCIP se fortalece. Em outras palavras, o DCl, além de se fortalecer isoladamente, também se fortalece pela combinação DCIP, demonstrando que, no período de consolidação do campo, o DP perde sua força quando usado isoladamente, devendo ser respaldado pelo $\mathrm{DCl}$. 0 Gráfico 4 resume essa trajetória.

Os discursos ganham ou perdem força em certas épocas, e os pesquisadores e as próprias revistas vão se utilizando deles por meio das estratégias de legitimidade de contribuição científica, visando construir trabaIhos que lhes permitam obter autoridade e legitimidade de modo a acumular capital simbólico, posicionando-se melhor no jogo de forças do campo. No fundo, todas as estratégias de legitimidade buscam alguma forma de obter o monopólio da verdade, isto é, da autoridade científica, argumentando essa verdade de diferentes formas, recorrendo a diferentes estratégias. 
Gráfico 4. Evolução das principais estratégias de legitimidade de contribuição científica em porcentagem sobre o total da produção - de 1960 a 2014

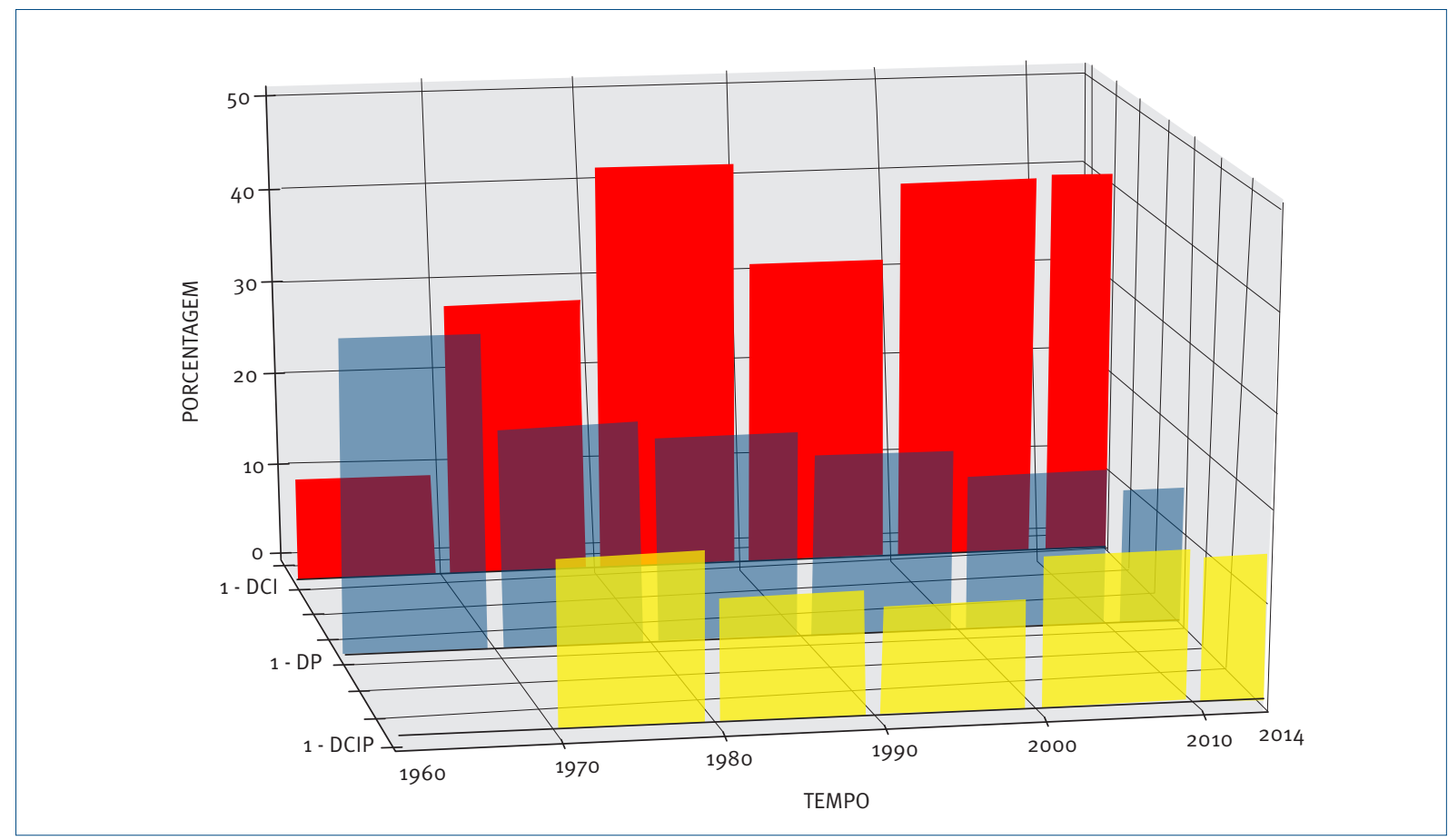

Fonte: Dados da pesquisa.

\section{REFLEXÕES FINAIS: O JOGO NO CAMPO CIENTÍFICO E O PAPEL DAS REVISTAS}

A análise empírica até então realizada demonstrou que o campo de Estudos Organizacionais anterior aos anos 2000 não tinha características que pudessem aproximá-lo de um campo científico do ponto de vista conceitual, uma vez que era caracterizado por um número reduzido de atores/jogadores institucionais e individuais e pela ausência de um jogo ou disputa entre eles.

Demonstramos que, com o crescimento dos atores do campo, pesquisadores, programas e revistas acadêmicas, possibilitado por recursos públicos crescentes, ocorreu a estruturação de um campo dinâmico que, por sua vez, demanda posicionamentos diferenciados dos diversos atores, definindo sua dinâmica de competição em torno de um objetivo comum - o monopólio da autoridade científica (Bourdieu, 1983, 2004; Fligstein \& McAdam, 2011, 2012).

Os posicionamentos refletem-se em diferentes combinações de programas, pesquisadores e revistas científicas, considerando os conceitos dos programas de pós-graduação, o estrato Qualis CAPES do periódico, o recebimento ou não de bolsa de produtividade CNPq, e as estratégias de legitimidade mais frequentemente utilizadas.

Destacamos três tipologias combinatórias de atores observados na disputa do campo científico no país. Os denominados "científicos" são os grupos de atores mais bem posicionados no campo, que recorrem frequentemente à estratégia de legitimidade $\mathrm{DCl}$, publicam internacionalmente ou nos periódicos mais bem-avaliados 
nacionalmente (alto extrato Qualis), estão vinculados a instituições estrangeiras ou com programas de pós-graduação de conceito 7 a 4, e parte deles é de bolsistas de produtividade CNPq. As "pontes" são grupos de atores que transitam entre duas estratégias de legitimidade, utilizando a combinação DCIP. Dividem-se entre publicações internacionais, mas também em periódicos nacionais de boa e média avaliação (A2 e B1), estão vinculados a instituições de programas de conceito 7 a 4, sendo alguns bolsistas de produtividade CNPq. Já os “locais” são os grupos de atores com posicionamento mais desfavorável no campo. Utilizam a estratégia de legitimidade DP, não publicam internacionalmente, mas sim nacionalmente, em alguns casos, em periódicos bem-avaliados (A2), mas, em outros casos, em periódicos de estratos mais baixos (B3), e estão vinculados a programas de conceito 6, 4, 3 ou mesmo não possuem vínculo a programas de pós-graduação.

Estas tipologias devem ser interpretadas como tipos ideais de atores-jogadores (individuais, redes, instituições e revistas) que tendem, dialeticamente, a mudar o posicionamento de acordo com a dinâmica do campo, ao passo que buscam influenciar essa dinâmica.

As revistas, como principal meio de veiculação da contribuição científica, desempenham um papel-chave na dinâmica competitiva do campo científico, uma vez que são ranqueadas e ajudam a "ranquear" pesquisadores e programas, promovendo a lógica de competição inerente ao jogo. Esse papel, no caso brasileiro, é estimulado pela lógica competitiva de CAPES/CNPq, que impõe a lógica de rankings a programas, pesquisadores individuais e revistas acadêmicas.

0 processo de crescimento quantitativo do campo acima relatado refletiu-se na multiplicação de todos os atores: programas, pesquisadores e revistas acadêmicas. Hoje, o campo de Administração no Brasil conta com mais de 300 revistas nacionais. 0 crescimento seguiu apenas a lógica de multiplicação de programas e pesquisadores, num movimento produtivista há tempos criticado por vários autores do campo, refletindo-se em periódicos que são irrelevantes do ponto de vista científico (Bertero et al., 2013; Rosa \& Romani-Dias, 2019).

Em busca de diferenciação, as revistas nacionais buscam responder à pressão atual para "internacionalização". O movimento é materializado de várias formas, conforme analisado por Rosa e Romani-Dias (2019a; 2019b): enquanto quase 60\% das revistas dos estratos maiores Qualis (A2) adotam publicações bilíngue ou em inglês, $73,33 \%$ dos periódicos do estrato B1 e 100\% para periódicos do estrato B5 publicam exclusivamente em português. Os autores notam que boa parte das revistas nacionais não atinge presença significativa nos principais indexadores nacionais (SciELO) e internacionais (Scopus, Web of Sciente, entre outros) e ainda apresenta métricas de baixo impacto em comparação com pares internacionais.

Ainda, as revistas mais bem classificadas nos indexadores internacionais tentem a coincidir e representam, em boa parte, revistas pioneiras do campo, ao exemplo da $R A E$ e $R A P$, indicando um papel importante para a reputação histórica e o investimento institucional no periódico. Por fim, a internacionalização está longe de se concretizar numa contribuição genuína do campo brasileiro no palco internacional, uma vez que ainda predomina um mimetismo temático e metodológico do contexto norte-americano (Peci \& Fornazin, 2017).

Tudo indica, entretanto, que a internacionalização, na medida em que se incorpora como um dos principais critérios de avaliação e ranking dos programas, pesquisadores e revistas, tornou-se o novo capital simbólico do campo de Administração, um novo recurso estratégico que diferencia os jogadores, na disputa pelo monopólio da autoridade científica. A dinâmica do campo muda, e os recursos são habilmente modificados para manter e responder à lógica competitiva do jogo do campo científico em ação. 


\section{REFERÊNCIAS}

Alcadipani, R., \& Bertero, C. O. (2012). Guerra Fría y enseñanza del management en Brasil: el caso FGV-EAESP. RAE-Revista de Administração de Empresas, 52(3), 284-299. doi: 10.1590/ So034-75902012000300002

Bardin, L. (2006). Análise de Conteúdo. 4. ed. Lisboa: Edições 70.

Barros, A. (2011). O desenvolvimento das escolas superiores de administração: Os saberes administrativos brasileiros no contexto de hegemonia estadunidense. Artigo apresentado no XXXV EnANPAD, Rio de Janeiro, RJ.

Barros, A., \& Carrieri, A. (2013). Ensino superior em administração entre os anos 1940 e 1950: Uma discussão a partir dos acordos de cooperação Brasil-Estados Unidos. Cadernos EBAPE.BR, 11(2), 256-273. doi: /10.1590/S1679-39512013000200005

Barros, A., Cruz, R., Xavier, W., \& Carrieri, A. (2011). Apropriação dos saberes administrativos: Um olhar alternativo sobre o desenvolvimento da área. RAM-Revista de Administração Mackenzie, 12(5), 43-67. doi: 10.1590/S1678 69712011000500003

Bertero, C. O. (2003). A problemática educação de administradores. RAE-Revista de Administração de Empresas, 43(2), 10-10. doi: 10.1590/S0034-75902003000200002V

Bourdieu, P. (1983). A economia das trocas linguísticas. In R. Ortiz (Org.), Bourdieu: Sociologia (Coleção Grandes Cientistas Sociais). São Paulo, SP: Ática.

Bourdieu, P. (1991) The Peculiar History of Scientific Reason. Sociological Forum, 6(1), 3-26.

Bourdieu, P. (1998). Escritos de Educação. 6. ed. Petrópolis: Vozes.

Bourdieu, P. (2004). Os Usos Sociais da Ciência. São Paulo: Unesp.

Burri, R. (2008). Doing Distinctions: boundary work and symbolic capital in Radiology. Social Studies of Science, 38(1), 35-62. doi: 10.1177/0306312707082021

Coelho, F., Olenscki, A. R., \& Celso, R. (2010). Da letargia ao realento: Notas sobre o ensino de graduação em administração pública no Brasil no entremeio da crise do Estado e da redemocratização no país (1983-1994). Artigo apresentado no IV EnAPG, Vitória, ES.

Coelho, F. S. (2006). Educação superior, formação de adminis tradores e setor público: Um estudo sobre o ensino de administração pública - em nível de graduação - no Brasil (Tese de doutorado, Escola de Administração de São Paulo da Fundação Getulio Vargas, São Paulo, SP).

Curado, I. B. (2001). O desenvolvimento dos saberes administrativos em São Paulo (Tese de doutorado, Fundação Getulio Vargas, São Paulo, SP).

Davis, G., \& Marquis, C. (2005). Prospects for organizations theory in the early twenty-first century: Institutional fields and mechanisms. Organization Science, 16(4), 332-343. doi: /10.1287/orsc.1050.0137
Fischer. T. (1984a). O ensino de administração pública no Brasil: Os ideais de desenvolvimento e as dimensões de racionalidade (1948-1984) (Tese de doutorado, Faculdade de Economia e Administração da Universidade de São Paulo, São Paulo, SP).

Fischer. T. (1984b). Administração pública como área de conhecimento e ensino. RAE-Revista de Administração de Empresas, 24(4), 278-288. doi: 10.1590/So034-75901984000400038

Fischer. T. (1993). A formação do administrador brasileiro na década de 90: Crise, oportunidade e inovações nas propostas de ensino. Revista de Administração Pública, 27(4), 11-20. doi: 10.1590/So034-75902003000200003v

Fischer. T. (2010). A perduração de um mestre e uma agenda de pesquisa na educação de administradores: Artesanato de si, memória dos outros e legados do ensino. Organização \& Sociedade, 17(52), 209-219. Recuperado de https://cienciasmedicasbiologicas.ufba.br/index.php/revistaoes/article/ view/11102

Fischer, T., Waiandt, C., \& Fonseca, R. L. (2011). A história do ensino em administração: contribuições teóricometodológicas e uma proposta de agenda de pesquisa. Revista de Administração Pública, 45(4), 911-939. doi: 10.1590/So034-76122011000400002

Fligstein, N., \& McAdam, D. (2011). Toward a general theory of strategic action fields. Sociological Theory, 29(1), 1-26. doi: 10.1111/j.1467-9558.2010.01385.x

Fligstein, N., \& McAdam, D. (2012). A theory of fields. New York, USA: Oxford University Press.

Gaskell, G., \& Bauer, M. W. (2005). Para uma prestação de contas pública: além da amostra, da fidedignidade e da validade. In M. W. Bauer, \& G. Gaskell (Eds.), Pesquisa qualitativa com texto, imagem e som: Um manual prático ( $4^{\mathrm{a}}$ ed.). Petrópolis, RJ: Vozes.

Gusfield, J. (1976). The literary rhetoric of science: Comedy and pathos in drinking driver research. American sociological review, 16-34. doi: 10.2307/2094370

Hong, W. (2008). Domination in a Scientific Field: capital struggle in a Chinese isotope lab. Social Studies of Science, 38(4), 543570. doi: $10.1177 / 0306312706092456$

Kirk, J., \& Miller, M. L. (1986). Reliability and validity in qualitative research. Londres, Inglaterra: Sage Publications.

Klenk, N. L., Hickey, G. M., \& MacLellan, J. I. (2010). Evaluating the social capital accrued in large research networks: The case of the Sustainable Forest Management Network (1995-2009). Social Studies of Science, 40(6), 931-960. doi: $10.1177 / 0306312710374130$

Locke, K., \& Golden-Biddle, K. (1997). Constructing opportunities for contribution: Structuring intertextual coherence and "problematizing" in organizational studies. Academy of Management Journal, 40(5), 1023-1062. doi: 10.5465/256926

Martin, J. L. (2003). What Is Field Theory? America Journal Sociology, 109, jul, 1-49. doi: 10.1086/375201 
Motta, F. P. (1983). A questão da formação do administrador. RAE-Revista de Administração de Empresas, 23(4), 53-55. doi: 10.1590/S0034-75901983000400005

Nicolini, A. (2003). Qual será o futuro das fábricas de administradores? RAE-Revista de Administração de Empresas, 43(2), 44-54. doi: 10.1590/So034-75902003000200003

Nicolini, A (2007). Aprender a Governar: a aprendizagem de funcionários públicos para as carreiras de Estado. Tese (Doutorado em Administração, Universidade Federal da Bahia. Salvador)

Peci, A., \& Alcadipani, R. (2006). Demarcação científica: Uma reflexão crítica. Organização \& Sociedade, 13(36), 145-161. doi: 10.1590/S1984-92302006000100008
Peci, A., \& Fornazin, M. (2017). The knowledge-building process of public administration research: A comparative perspective between Brazil and North American contexts. International Review of Administrative Sciences, 83(1_suppl), 99-119. doi: $10.1177 / 0020852316637660$

Rosa, R. A., \& Romani-Dias, M (2019a). Indexação de periódicos e a política de avaliação científica: Uma análise do campo de administração, contabilidade e turismo no Brasil. International Journal of Professional Business Review, 4, 1-17. doi: 10.26668/businessreview/2019.v4i2.168

Rosa, R. A., \& Romani-Dias, M. (2019b). A presença e o impacto de periódicos brasileiros da área de administração, contabilidade e turismo em bases internacionais e nacionais. Revista Eletrônica de Ciência Administrativa (RECADM), 18, 327-348. doi: 10.21529/RECADM.2019014

\section{CONTRIBUIÇÃO DAS AUTORAS}

Alketa Peci e Lilian Alfaia Monteiro trabalharam na conceitualização e abordagem teórica-metodológica. A revisão teórica foi conduzida por Alketa Peci e Lilian Alfaia Monteiro. Lilian Alfaia Monteiro coletou os dados da pesquisa e a análise foi realizada em conjunto pelas autoras. Todas as autoras participaram da redação e revisão final do manuscrito. 